\title{
Adult Poisoning Cases in Ankara: Capital City of Turkey*
}

\author{
Cemil Kavalci $^{1 \#}$, Ali Demir ${ }^{1}$, Engin Deniz Arslan ${ }^{1}$, Fevzi Yilmaz $^{1}$, Tamer Durdu ${ }^{1}$, Cihat Yel $^{1}$, \\ Gülsüm Kavalci², Muhittin Serkan Yilmaz ${ }^{1}$ \\ ${ }^{1}$ Numune Training and Research Hospital, Emergency Department, Ankara, Turkey; ${ }^{2}$ Yenimahalle State Hospital, Anesthesia De- \\ partment, Ankara, Turkey. \\ Email: "cemkavalci@yahoo.com, demir21@gmail.com,mdengin@yahoo.com, fevzi_yilmaz2002@yahoo.com, \\ setam49@hotmail.com,yelc@yahoo.com,gkavalci@yahoo.com,msyilmaz@yahoo.com
}

Received September $24^{\text {th }}, 2012$; revised November $9^{\text {th }}, 2012$; accepted November $25^{\text {th }}, 2012$

\begin{abstract}
Poisoning is the disruption of functions of a living organism by any agent. The aim of this study is to identify the clinical and demographic characteristics of intoxication cases admitted to the Numune Training and Research Hospital emergency department. Characteristics such as age and gender of the patients, intoxication agents, and the results (discharge, forwarding, hospitalization, death, etc.) were recorded to the prepared form. Data were assessed with the SPSS 15.0 software package and expressed. Quantitative variables were summarised as mean \pm standard deviation. Frequency and percent distribution were used for the evaluation of data. The chi-squared test was used for comparison of the quailtative variables. $p<0.05$ was accepted significant. The mean age of the receiving 651 poisoned patients was $32.04 \pm$ 12.24 years. Of them, $67.7 \%$ were female. The most causes of poisoning agents were a pharmaceuticals $(79.4 \%)$, carbonmonoxide $(8.9 \%)$ and alcohols $(7.1 \%)$. Gastric lavage was performed in $76 \%$ patients. Activated charcoal was administered in $81 \%$ patients. Antidotes treatment was applied in $7.4 \%$ patients. Most patients were evaluated and then treated and discharged from the ED (91.9\%).
\end{abstract}

Keywords: Emergency; Poisoning; Pharmaceuticals; Clinical and Demographic Characteristics

\section{Introduction}

Poisoning is the disruption of functions of a living organism by any agent [1]. Toxic substances have been used for centuries for suicide and/or homicide purposes. Toxic exposures to drugs and chemicals are among the most frequent reasons for Emergency Department (ED) visits in most countries [2-4] and a significant cause of morbidity and mortality worldwide [5]. Intoxication cases exhibit regional differences in terms of demographic characteristics, intoxication fashion and agents to be exposed. However, the causes and patterns of poisonings vary in different countries [4,5]. Clinical manifestations of poisoning patients between asymptomatic and death changes according to ingested agent [1].

The aim of this study is to identify the clinical and demographic characteristics of intoxication cases admitted to the Numune Training and Research Hospital emergency department.

\section{Material and Methods}

Patients admitted to Numune Training and Research Hospital between the dates of January 2011 and January 2012

\footnotetext{
*Conflict interest: The authors declare no conflict interest.

${ }^{\#}$ Corresponding author.
}

were evaluated retrospectively. Characteristics such as age and gender of the patients, intoxication agents, and the results (discharge, forwarding, hospitalization, death etc.) were recorded to the prepared form.

Poisons involved in the exposure were classsified into one of five categories: pharmaceuticals, gases, pesticides, corrosives, alcohols. Pharmaceuticals were subcategorised into antidepressants, analgesics, other psychotropic agents (including antipsychotics, benzodiazepins, lithium, etc.), antiepileptics, antibiotics, antihypertensives, antihistamines, anti-ulcer drugs, others (including vitamins, antiemetics, antidyspeptic drugs, antidiabetics, hormones, skeletal muscle relaxants, warfarin, drugs for the common cold, etc.), and unidentifiable pharmaceuticals. The number of ingested pharmaceuticals was also recorded Data were assessed with the SPSS 15.0 software package and expressed. Quantitative variables were summarized as mean \pm standard deviation. Frequency and percent distribution were used for the evaluation of data. The chisquared test was used for comparison of the qualitative variables. $p<0.05$ was accepted significant.

\section{Results}

Of the 165,028 adult patients presenting to the ED during 
the 1-year period, $651(0.004 \%)$ were cases related to poisoning.

The mean age of the receiving 651 poisoned patients was $32.04 \pm 12.24$ years. Of them, $67.7 \%$ were female. The mean age of female and male patients was $31.62 \pm$ 12.20 years and $32.94 \pm 12.32$ years respectively. There was no statistically significant difference according to gender $(p>0.05)$. In terms of age groups, most of our patients $(38.6 \%)$ were under 26 years of age (Table 1 ).

The most causes of poisoning agents was a pharmaceuticals $(79.4 \%, 517$ cases). The distribution of poisoning agents was shown on the Table 2 . With in the category of pharmaceuticals, analgesics were involved most often, followed by antidepressants (Table 2).

$57.8 \%$ of the patients were intoxicated by a single agent, whereas $12.6 \%$ were more than one (Table 3 ).

Gastric lavage was performed in $76 \%$ patients followed by activated charcoal administration. In additional, $5 \%$ of patients received only activated charcoal. Specific antidote treatment was applied in $7.4 \%$ patients.

Most patients were evaluated and then treated and discharged from the ED (91.9\%), while $8.1 \%$ were admitted to the hospital. No patients died due to poisoning.

Table 1. Demographic factors of patients.

\begin{tabular}{cccc}
\hline Demographic character & $\mathrm{n}$ & $\%$ & $p$ value \\
\hline Gender & 210 & 32.3 & $>0.05$ \\
Male & 441 & 67.7 & \\
Female & & & \\
Age groups & 251 & 38.6 & \\
$15-25$ & 200 & 30.7 & \\
$26-35$ & 109 & 16.7 & $<0.001$ \\
$36-45$ & 61 & 9.4 \\
$46-55$ & 17 & 2.6 \\
$56-65$ & 13 & 2.0 \\
\hline
\end{tabular}

Table 2. Substance due to poisoning.

\begin{tabular}{ccc}
\hline Substance & $\mathrm{n}$ & $\%$ \\
\hline Pharmatic & 517 & 79.4 \\
Alcohol & 46 & 7.1 \\
Pestisid & 18 & 2.8 \\
Carbonmonoksid & 58 & 8.9 \\
Corosives & 12 & 1.8 \\
\hline
\end{tabular}

Table 3. Pharmaceutical agents (one or multiple) involved in the poisonings.

\begin{tabular}{ccc}
\hline Pharmaceuticals & $\mathrm{n}$ & $\%$ \\
\hline Number of agents & 376 & 57.8 \\
1 & 82 & 12.6 \\
2 & 28 & 4.3 \\
3 & 28 & 4.3 \\
$4+$ & 137 & 21 \\
Unidentifiable & 180 & 27.6 \\
Analgesic & 114 & 17.5 \\
Antidepresant & 25 & 3.8 \\
Other psicotropic & 19 & 2.9 \\
Antiepileptic & 36 & 5.5 \\
Antibiotic & 39 & 6 \\
Antihypertensives & 14 & 2.2 \\
Antihistamines & 20 & 3.1 \\
Anti-Ulcer & 47 & 7.2 \\
Others & 137 & 21 \\
Unidentifiable & & \\
\hline & & \\
\hline
\end{tabular}

\section{Discussion}

Poisonings are important health problems leading to mortality and morbidity when they are not treated in time. Suicide is the second most common cause of death among the adolescent and young adults [1].

In a study of adult poisoning cases in Canada, acute intoxications accounted for $0.7 \%$ of ED visits [6]. Hanssens et al. showed that acute poisoning cases were $0.18 \%$ of total emergency admissions [7]. Another study on poisonings performed in England revealed that 1.2\% of ED visits were due to acute poisoning [8]. Our ED had a proportion of acute poisoning cases $(0.004 \%)$, reduced that $(0.7 \%-2.4 \%)$ reported from EDs in other parts of Turkey [9-13]. Increased patient number may have been in these results.

As in other reports, the majority of our patients were young; $38.6 \%$ were under 26 years of age, similar to proportions in two international studies and in two studies from Turkey [7-10]. However, in the study of Tüfekçi et al. [14], the highest number of poisonings occurred in the 28 - 37 year-old age group in males and in the $38-47$ year-old age group in females. The female: male ratio in our patients was 2.1. In previous reports from Turkey, the female:male ratio varied between 1.7 and 3.0 [9, $11,13]$. Interestingly, this ratio has been reported to be lower (approximately 1:1) in various developed countries 
$[6,15,16]$. Our results were consistent with literature. We suggest that economic and social problems such as unemployment, marriage etc. are affecting this age group more usually.

The substances involved in most of the poisonings in our study were pharmaceutical agents $(79.4 \%)$, which is in agreement with reports from other regions in Turkey [9-13]. In studies from other countries, pharmaceuticals were also found to be the most common agents involved in acute poisoning [15-18]. Regarding the class of pharmaceutical involved in poisonings in Turkey, analgesics were reported to be the most frequently ingested agents in some studies (27.6\% in our study) [9-12], whereas antidepressants were most commonly used in the study by Baydin et al. [13], as was the case in our study (17.5\%). Benzodiazepines were the most commonly ingested agents among medicinal drug poisonings in Finland, Iran, Canada and Norway $[4,6,17,18]$. TCAs and SSRIs are easily available without a prescription but a prescription is needed to purchase benzodiazepines in Turkey.

The second most common type of poisoning in our study was $\mathrm{CO}$ intoxications $(8.9 \%)$. CO poisoning is still a serious problem in Turkey, especially during autumn and winter. $\mathrm{CO}$ poisoning occurs due to dysfunctioning coal stoves, inadequate maintenance of chimney systems, or deliberate closure of the flue at night to prevent cold air from entering the home. Thus, whole families may present to the ED when strong winds prevent the exhaust of normal smoke from the coal stoves. The percentage of $\mathrm{ED}$ admissions due to $\mathrm{CO}$ poisoning in previous Turkish reports varied between $7 \%$ and $14 \%[12,15,19]$.

Alcohols were the third most common toxic agent in our study (7.1\%). Alcohols poisoning ratio was $3.1 \%$ $18 \%$ in previous study [20-23]. Our results were consistly with literature. In islamic communities alcoholconsumption is lower than western communities so intoxication rates are migth be lower in Turkey.

Pesticides were the fourth most common toxic agent. Over $90 \%$ of who were poisoned with organophosphates. These caused no deaths in our study. In a comprehensive review of 76 articles published between 1980 and 1999, Eddlestone reported that organophosphate pesticides were responsible for the majority of deaths in most series of self-poisoning cases, particularly those from rural areas [24]. As such, pesticides re often sold in local markets and kept in homes $[25,26]$. Studies from non-agricultural areas in Turkey, such as Ankara and Istanbul, reported the percentage of poisonings involving pesticides to be much lower, $0.9 \%$ and $1.6 \%$ respectively $[11,14]$, while those from agricultural areas reported involvement of pesticides in $12 \%-26 \%$ of cases [13,27].

Corrosive agents were ingested by $1.8 \%$ of our patients. Hipochlorid is cheap, widely used and may be ingested accidentally or intentionally. The incidence of corrosive ingestion was reported to be $2 \%-2.2 \%$ in previous study $[3,11]$.

The ratio of intoxication by a single agent was reported as $55 \%-74 \%$ in previous study $[10,21,22] 57.8 \%$ of our patients were intoxicated by a single agent. Our results are similar to literature. Suicidal attempts commonly are impulsive and patients ingest single agent they could reach rather than multiple agents.

Gastric decontamination, active charcoal and specific antidote treatment have an important place in the treatment of the intoxication cases [28]. Gastric decontamination recommended for patients with in one hour after ingestion. Administration of single-dose activated charcoal to adsorb ingested toxins is generally recommended for the ingestion of life-threatening poisons for which no adequate antidotal therapy is available and when the charcoal can be administered within 1 hour of poisoning [28].

The death ratios were reported as $0 \%$ to $5.8 \%$ in the literature [10-12,21]. Our results are consistent with the literature $(0 \%)$. The early interventions and the proper antidote administration in the intoxication cases decrease the death ratios. Training for the treatment of poisoning should be provided to physcians.

\section{Conclusion}

Pharmaceutical agents, CO, and alcohol were the three most common poisoning agents encountered in our ED during the study period. Poisoning is common in adults in our area; the risk being highest in females and younger adults. The data provide important information on characteristics of acute poisoning in this particular region of Turkey and may guide activities such as professional training, preventive measures, community education and new research.

\section{REFERENCES}

[1] P. M. Wax, "History," In: L. R. Goldfrank and N. E. Flomenbaum, Eds, Toxicologic Emergency, 6th Edition, McGraw-Hill, New York, 2006, pp. 1-14.

[2] H. A. Spiller, S. Appana and G. N. Brock, "Epidemiological Trends of Suicide Andattempted Suicide by Poisoning in the US: 2000-2008," Legal Medicine, Vol. 12, No. 4, 2010, pp. 177-183. doi:10.1016/j.legalmed.2010.04.005

[3] J. Kristinsson, R. Palsson, G. A. Gudjonsdottır, M. Blondal, S. Gudmundsson and C. P. Snook, "Acute Poisonings in Iceland: A Prospective Nationwide Study," Clinical Toxicology, Vol. 46, No. 2, 2008, pp. 126-132. doi:10.1080/15563650701438268

[4] O. Lapatto-Reiniluoto, K. T. Kivistö, S. P. Sintonen, K. Luomanmaki and P. J. Neuvonen, "A Prospective Study of Acute Poisonings in Finnish Hospital Patients," $\mathrm{Hu}$ man \& Experimental Toxicology, Vol. 17, No. 6, 1998, pp. 


\section{7-311. doi:10.1191/096032798678908864}

[5] S. M. Lam, A. C. W. Lau and W. W. Yan, "Over 8 Years Experience on Severe Acute Poisoning Requiring Intensive Care in Hong Kong, China," Human \& Experimental Toxicology, Vol. 29, No. 9, 2010, pp. 757-765. doi:10.1177/0960327110361753

[6] P. Chow, M. G. Tierney and G. E. Dickinson, "Acute Intoxications: Cases Presenting to an Adult Emergency Department," Canadian Family Physician, Vol. 38, No. 38, 1992, pp. 1379-1382.

[7] Y. Hanssens, D. Deleu and A. Taqi, "Etiologic and Demographic Characteristics of Poisoning: A Prospective Hospital-Based Study in Oman," Clinical Toxicology, Vol. 39, No. 4, 2001, pp. 371-380. doi:10.1081/CLT-100105158

[8] S. H. Thomas, L. Bevan, S. Bhattacharyya, M. G. Bramble, K. Chew, J. Connolly, et al., "Presentation of Poisoned Patients to Accident and Emergency Departments in the North of England," Human \& Experimental Toxicology, Vol. 15, No. 6, 1996, pp. 466-470. doi:10.1177/096032719601500602

[9] S. Goksu, C. Yildirim, H. Kocoglu, A. Tutak and U. Oner, "Characteristics of Acute Adult Poisoning in Gaziantep, Turkey," Clinical Toxicology, Vol. 40, No. 7, 2002, pp. 833-837. doi:10.1081/CLT-120016953

[10] L. Avsarogullari, V. Senol, O. Akdur, A. Akin, P. Durukan and S. Özkan, "Characteristics of Acute Adult Poisonings in a University Hospital Emergency Department in Central Turkey: A Three-Year Analysis, " Journal of the Pakistan Medical Association, Vol. 62, No. 2, 2012, pp. 129-133.

[11] Z. Özköse and F. Ayoglu, "Etiological and Demographical Characteristics of Acute Adult Poisoning in Ankara, Turkey," Human \& Experimental Toxicology, Vol. 18, No. 10, 1999, pp. 614-618. doi:10.1191/096032799678839446

[12] A. Pinar, J. Fowler and G. R. Bond, "Acute Poisoning in Izmir, Turkey-A Pilot Epidemiologic Study," Clinical Toxicology, Vol. 31, No. 4, 1993, pp. 593-591. doi:10.3109/15563659309025764

[13] A. Baydin, T. Yardan, D. Aygun, Z. Doganay, C. Nargis and O. Incealtin, "Retrospective Evaluation of Emergency Service Patients with Poisoning: A 3-Year Study," Advances in Therapy, Vol. 22, No. 6, 2005, pp. 650-658. doi:10.1007/BF02849959

[14] I. B. Tüfekçi, A. Çurgunlu and F. Sirin, "Characteristics of Acute Adult Poisoning Cases Admitted to a University Hospital in Istanbul," Human \& Experimental Toxicology, Vol. 23, No. 7, 2004, pp. 347-351. doi:10.1191/0960327104ht460oa

[15] K. Hawton, J. Fagg and S. Simkin, "The Epidemiology of Attempted Suicide in the Oxford Area, England (19891992)," Crisis, Vol. 15, No. 3, 1994, pp. 123-135.

[16] M. A. Bjornaas, K. E. Hovda, H. Mikalsen, E. Andrew, N. Rudberg, O. Ekeberg, et al., "Clinical vs. Laboratory Identification of Drugs of Abuse in Patients Admitted for Acute Poisoning," Clinical Toxicology, Vol. 44, No. 2, 2006, pp. 127-134. doi:10.1080/15563650500514384
[17] M. Islambulchilar, Z. Islambulchilar and M. H. KargarMaher, "Acute Adult Poisoning Cases Admitted to a University Hospital in Tabriz, Iran," Human \& Experimental Toxicology, Vol. 28, No. 4, 2009, pp. 185-190. doi:10.1177/0960327108099679

[18] K. E. Hovda, M. A. Bjornaas, K. Skog, A. Opdahl, P. Drottning, O. Ekeberg, et al., "Acute Poisonings Treated in Hospitals in Oslo: A One-Year Prospective Study (I): Pattern of Poisoning," Clinical Toxicology, Vol. 46, No. 1, 2008, pp. 35-41. doi:10.1080/15563650601185969

[19] F. Le Pont, L. Letrilliart, V. Massari, Y. Dorléans, G. Thomas and A. Flahault, "Suicide and Attempted Suicide in France: Results of a General Practice Sentinel Network, 1999-2001," British Journal of General Practice, Vol. 54, No. 501, 2004, pp. 282-284.

[20] C. Kavalci, Y. Çevik, M. Özer, P. Durukan, I. İkizceli and G. Kavalci, "Characteristics of Poisoning Cases in Ankara, Turkey," The Internet Journal of Emergency Medicine, Vol. 5, No. 1, 2009.

[21] M. Pekdemir, M. Yiildiz, P. Durukan and C. Kavalci, "Evaluation of Adult Intoxication Cases Applied to Emergency Department," Toksikoloji Dergisi, Vol. 2, 2004, pp. 41-48.

[22] T. J. Wiegand, P. M. Wax, T, Schwartz, Y. Finkelstein, R. Gorodetsky and J. Brent, "On Behalf of the Toxicology Investigators Consortium Case Registry Investigators. The Toxicology Investigators Consortium Case Registry-The 2011 Experience," Journal of Medical Toxicology, Vol. 8, No. 4, 2012, pp. 360-377.

[23] C. Lund, B. Teige, P. Drottning, B. Stiksrud, T. O. Rui, M. Lyngra, O. Ekeberg, D. Jacobsen and K. E. Hovda, “A One-Year Observational Study of All Hospitalized and Fatal Acute Poisonings in Oslo: Epidemiology, Intention and Follow-Up," BMC Public Health, Vol. 12, 2012, p. 858. doi:10.1186/1471-2458-12-858

[24] M. Eddlestone, "Patterns and Problems of Deliberate Self-Poisoning in the Developing World," QJM, Vol. 93, No. 11, 2000, pp. 715-731. doi:10.1093/qjmed/93.11.715

[25] Y. Yurumez, P. Durukan, Y. Yavuz, I. Ikizceli, L. Avsarogullari, S. Ozkan, et al., "Acute Organophosphate Poisoning in University Hospital Emergency Room Patients," Internal Medicine, Vol. 46, No. 13, 2007, pp. 965-969. doi:10.2169/internalmedicine.46.6304

[26] M. Güven, M. Sungur, F. Tanrıverdi, B. Eser and Z. Kekeç, "Evaluation of the Patients with Acute Intoxication," Turkish Journal of Medical Sciences, Vol. 32, No. 2, 2002, pp. 169-172.

[27] G. Seydaoglu, S. Satar and N. Alparslan, "Frequency and Mortality Risk Factors of Acute Adult Poisoning in Adana, Turkey, 1997-2002," Mount Sinai Journal of Medicine, Vol. 72, No. 6, 2005, pp. 393-401.

[28] N. E. Flomenbaum, L. R. Goldfrank, R. S. Hoffman, M. A. Howland, N. A. Lewin and L. S. Nilson, "Principles of Managing the Poisoned or Overdosed Patient," In: L. R. Goldfrank and N. E. Flomenbaum, Eds., Toxicologic Emergency, 8th Edition, McGraw-Hill, New York, 2006, pp. $42-50$. 